\title{
PERSISTENT ECTOPIC AURICULAR TACHYCARDIA IN CHILDREN
}

\author{
BY \\ J. D. HAY AND S. E. KEIDAN \\ From the Department of Child Health, University of Liverpool \\ Received November 5, 1951
}

Paroxysmal tachycardia is not uncommon in infancy and early childhood. The paroxysms are usually of short duration and may be characterized by attacks of abdominal pain and vomiting, sometimes associated with collapse (Hubbard, 1941). Prolonged attacks in children have been reported by Parkinson and Papp (1947) and by Miller and Perelman (1945).

Three further cases of prolonged tachycardia are described in this paper. They are of interest because in one there was no evidence of a normal sino-auricular node and in two there appeared to be two ectopic foci; in none of the three did persistent tachycardia at a high rate over a long period lead to the development of cardiac failure.

Case 1. Ann W., aged 6 years, was first seen when 14 months, because of a rapid heart rate which had been noted by her family doctor for the first time at 6 months of age. She was symptomless.

Examination showed a regular pulse rate of 180 a minute, a very soft systolic murmur audible down the left border of the sternum, and radiological evidence of slight cardiac enlargement involving especially the conus of the right ventricle. An electrocardiogram showed an ectopic auricular tachycardia of 200 a minute with inverted P waves in leads II and III (Fig. 1). At 16 months of age an unsuccessful attempt was made to establish normal rhythm by the successive exhibition of digoxin, strophanthin, and quinidine sulphate.

During the next four years she remained symptomless. The tachycardia persisted, although at a slightly lower rate, and cardiograms showed no change. At 6 years of age a further attempt was made to establish normal rhythm. Digoxin was given orally, an initial daily dose of $0.25 \mathrm{mg}$. being increased gradually until she was taking $0.82 \mathrm{mg}$. daily which was maintained for 18 days without symptoms of toxicity. Normal complexes appeared in the electrocardiogram for the first time on the second day of treatment. By the fourth day periods of normal rhythm at about 60 a minute were alternating with the ectopic rhythm at 140 a minute (Fig. 2). The beats at the slower rate showed upright $\mathbf{P}$ waves in lead II and some biphasic and some negative $\mathbf{P}$ waves in lead III; slight S-T depression was also present. At the end of 43 days treatment normal rhythm appeared to be well established with no further ectopic beats and no S-T depression. The dose was then gradually reduced until digoxin was discontinued altogether after 88 days of treatment during which she had taken a total of $48 \mathrm{mg}$.

Within one week of complete withdrawal of the drug, paroxysms of the ectopic rhythm were again observed. Digoxin was, therefore, restarted and it has been found that $0.5 \mathrm{mg}$. daily will maintain normal rhythm (Fig. 3) while with a smaller dose the ectopic rhythm tends to recur.

Case 2, Mary M., aged $3 \frac{1}{2}$ years, was first seen with a history of recurring attacks of abdominal pain and vomiting for three months. Physical examination on this occasion showed no abnormality, but when seen again three weeks later she was having a further attack. The pulse rate was then found to be 200 a minute. She was pale and slightly cyanosed with raised jugular venous pressure and enlargement of the liver; there was no œdema or congestion of the lungs. The apex beat was in the fifth space, three and a half inches from the mid-line; the heart sounds were normal and no 


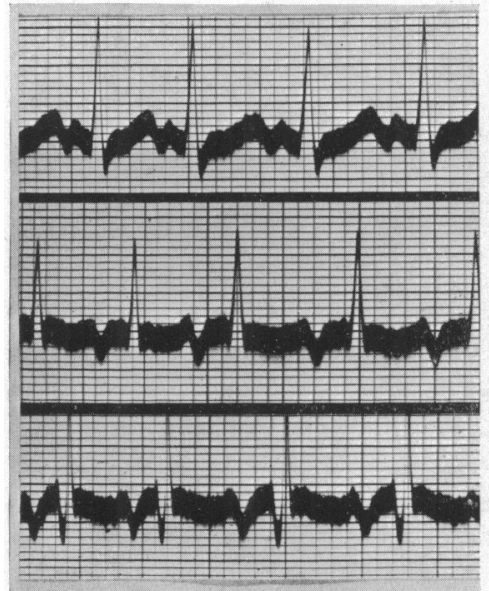

FIG. 1.-Case $1(21 / 2 / 47)$, aged 14 months. Ectopic auricular tachycardia. Rate 200 a minute.

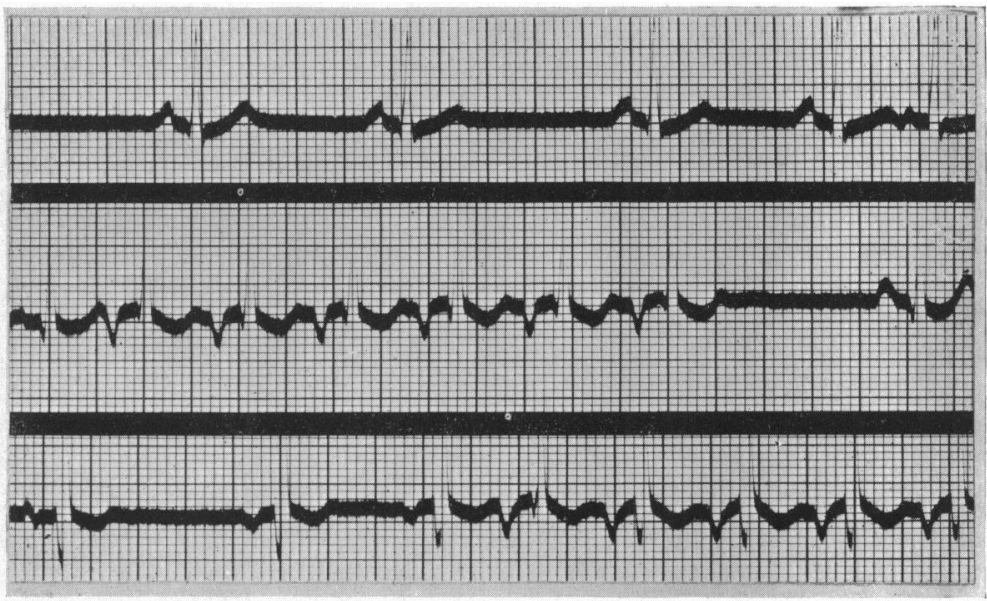

FIG. 2.-Case $1(23 / 2 / 51)$, aged 6 years. During digitalization. Periods of normal S-A rhythm and of ectopic auricular rhythm.

murmurs were detected. The heart rate was not affected by carotid sinus pressure or by an injection of prostigmine $(0.5 \mathrm{mg}$.).

The cardiogram (Fig. 4) showed auriculoventricular nodal tachycardia at a rate of 270 a minute. Digoxin was given by mouth in doses of $0.25 \mathrm{mg}$. 6-hourly. Within 24 hours the pulse rate had fallen to 80 a minute and there were frequent premature beats. After 48 hours the pulse rate was 50 a minute and there were coupled beats at the apex. A cardiogram (Fig. 5) at 72 hours showed an auricular tachycardia of 180 a minute with prolongation of the P-R interval and a 2:1 auriculoventricular block. Digoxin was then discontinued. For a short time after this the pulse was quite irregular, but during the rest of her stay in hospital it remained regular at a rate of 120 a minute.

The signs of cardiac failure disappeared as the pulse rate fell and she had no recurrence of abdominal pain while under observation. The apex beat remained outside the nipple line, the sounds were normal and there were no murmurs.

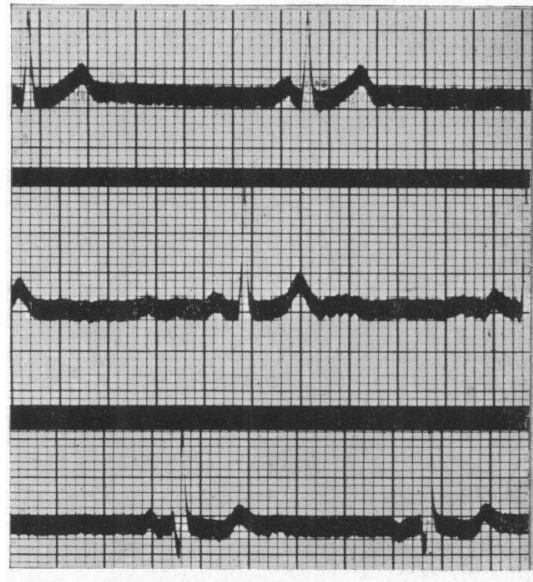

FIG. 3.-Case $1(5 / 6 / 51)$. Fully digitalized. Normal S-A rhythm.

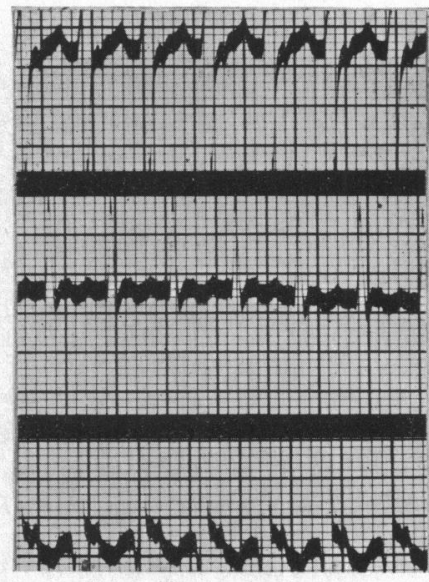

FIG. 4.-Case 2 (3/10/50). Supraventricular (A-V nodal) tachycardia.

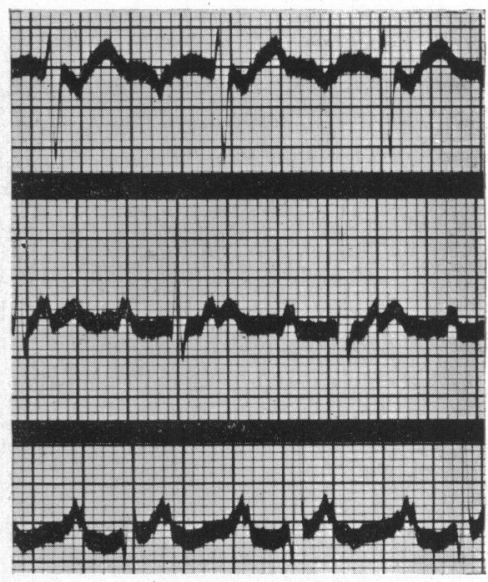

Fig. 5.-Case 2 (6/10/50). Auricular tachycardia. 2:1 auriculoventricular response; inverted $\mathbf{P}$ waves; prolonged P-R interval. 


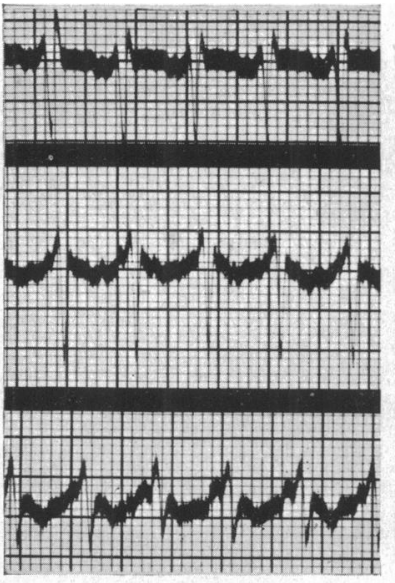

Fig. 6.-Case 2 (3/11/50). During carotid sinus pressure. $\mathbf{P}$ waves upright in first two complexes, subsequently inverted.

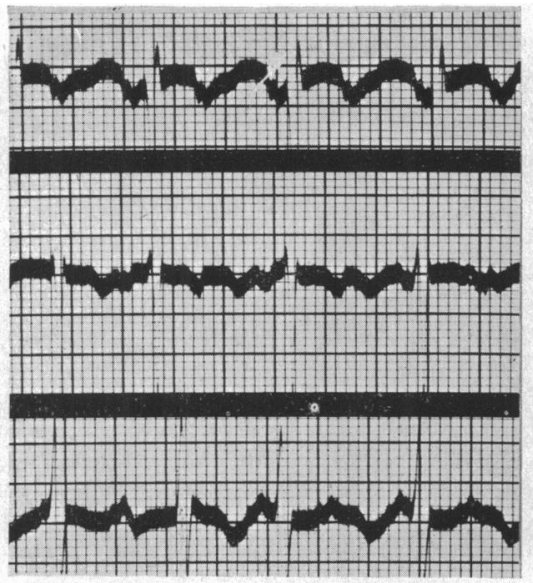

Fig. 7.-Case $2(25 / 5 / 51)$. Auricular tachycardia. 2:1 auriculo-ventricular responses; occasional supraventricular extrasystoles.

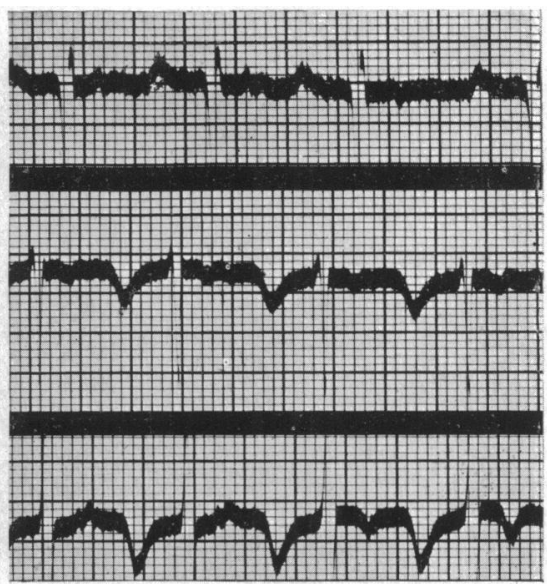

Fig. 8.-Case 3 (19/5/50). Supraventricular (A-V nodal) tachycardia.

A cardiogram one month after admission showed persisting inversion of the $P$ wave in lead 1 with a 1:1 ventricular response and a normal $P-R$ interval. Carotid sinus pressure temporarily restored the $P$ wave to normal but it inverted again while the pressure was still being applied (Fig. 6). She remained quite free from symptoms over the next few months and no treatment was given. The pulse remained regular at a rate of 150 a minute.

Seven months after her first attendance she had another attack of abdominal pain and vomiting and her mother noticed that her heart was beating rapidly. She was seen by her family doctor two days later and was given digoxin $0.25 \mathrm{mg}$. b.i.d. by mouth. When seen by one of us, two days later, the symptoms had subsided. She looked well and was very active and there were no signs of cardiac failure. The pulse rate was about 100 a minute with frequent premature beats. A cardiogram (Fig. 7) showed an auricular rate of 240 a minute, a 2:1 ventricular response, and occasional supraventricular extrasystoles. The $\mathrm{P}$ waves remained abnormal in shape and direction.

Case 3., Alan L., aged 11 years, was admitted to hospital with a history of " shivering" for 9 days and abdominal pain and vomiting for 4 days. Eighteen months previously he had been in hospital with tuberculous osteitis of the right femur. The pulse rate was only recorded for a short period and was then said to be normal.

At 6 years of age he had been attended by his family doctor for acute bronchitis and his mother had been told that he had a " damaged heart."

On admission to hospital he appeared pale but not acutely ill and there were no signs of cardiac failure. The radial pulse was difficult to feel but the rate was about 180 a minute and the rhythm regular. The systolic blood pressure was $105 \mathrm{~mm}$. $\mathrm{Hg}$; the diastolic could not be measured. The apex beat was not displaced, the sounds were normal, and there were no murmurs. The ventricular rate was about 200 a minute. It was not affected by pressure on the carotid sinuses or on the eyeballs; both Valsalva's and Müller's manœuvres and changes of posture were without effect. A cardiogram (Fig. 8) showed auriculo-ventricular nodal tachycardia.

Quinidine by mouth had no effect but a short course of digoxin did slow the heart rate by producing a 2:1 auriculo-ventricular block (Fig. 9). The cardiogram also showed that the tachycardia had now become auricular rather than nodal in origin. A further course of digoxin was given one month later, but as an effective dose caused nausea and vomiting together with the appearance of frequent ventricular extrasystoles (Fig. 10) treatment was abandoned. Subsequent records have 


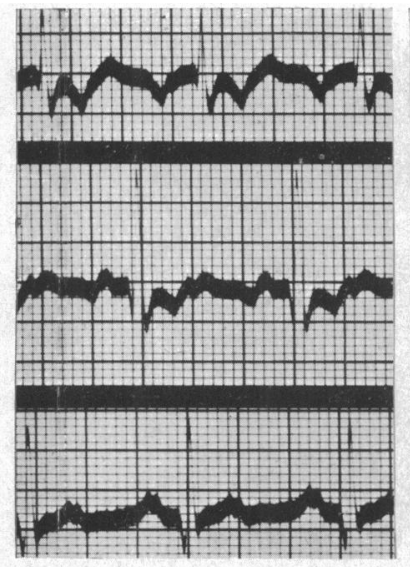

Fig. 9.-Case $3(31 / 5 / 50)$. Auricular tachycardia with 2:1 ventricular response.

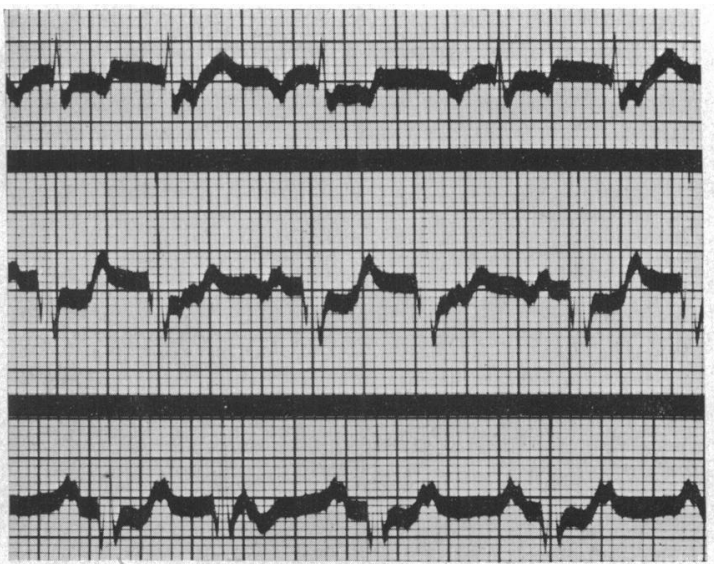

FIG. 10.-Case $3(18 / 6 / 50)$. Auricular tachycardia with varying degree of $\mathrm{A}-\mathrm{V}$ block and ventricular extrasystoles.

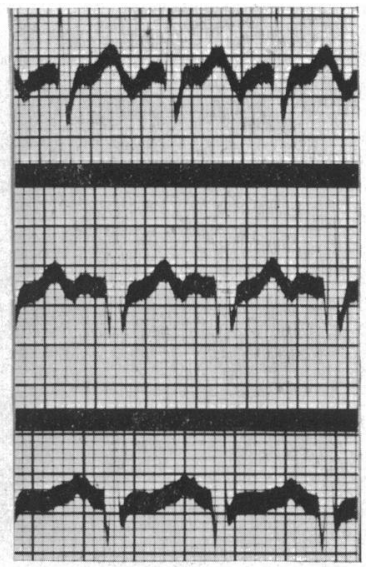

FIG. 11.-Case $3(25 / 5 / 51)$. Auricular tachycardia with $1: 1$ ventricular response.

shown a regular tachycardia with 1:1 rhythm and persistent inversion of the $\mathrm{P}$ waves in lead 1 (Fig. 11).

He received further treatment for the tuberculous osteitis of the femur and was eventually discharged with a walking calliper. During the last ten months he has otherwise been well with no symptoms of cardiac failure and the pulse rate has remained at about 150 a minute.

\section{Discussion}

The main point of interest in these three cases is the persistence of an auricular ectopic tachycardia at a high rate over a prolonged period without the development of cardiac failure. Campbell (1947) states that nothing corresponding to established tachycardia has been described but two of these cases are very suggestive of such a condition.

In most instances of prolonged tachycardia that have been reported cardiac failure has developed at some time during the attacks (Maddox, 1937; Miller and Perelman, 1945; Herson and Willington, 1947; and Claiborne, 1950). On the other hand several cases have been described in which cardiac failure did not develop after periods of tachycardia varying from 3 to 43 years (Miller and Perelman, 1945; Weiss and McGuire, 1936).

In Case 1 an auricular tachycardia of 200 a minute was first observed at 14 months and subsequent observation during the next five years showed an average rate of about 160 a minute: cardiac failure did not occur. In Case 2 an auricular tachycardia of 120 a minute persisted for seven months without cardiac failure developing. A short paroxysm of auriculo-ventricular nodal tachycardia at 200 a minute did, however, lead to failure. In Case 3 the ectopic auricular rate has varied from 150 to 180 a minute and there has never been any evidence of cardiac failure.

The absence of cardiac failure during very prolonged periods of marked tachycardia in our cases may be regarded as supporting the contention of Weiss and McGuire (1936) that high cardiac rates up to 150 a minute are not necessarily dangerous provided the heart is otherwise normal. The early evidence of cardiac enlargement in Case 1 may indicate, however, an adverse effect of the tachycardia. On the other hand the enlargement may be due to a congenital cardiac lesion of which there is no other evidence.

In Case 3 another point of interest is the lack of any evidence of the existence of a normal sinoauricular node. In nearly all the published cases, except that of Alimurung et al. (1950), normal sino-auricular rhythm has been known to be present before the onset of the paroxysm or has been 
demonstrated after the attack. In a few cases where a patient died during an attack or the attack was of long duration the only evidence of the existence of the node was the occurrence of occasional normal sino-auricular beats (Miller and Perelman, 1945). In some cases where a rapid ectopic rhythm was associated with the sudden onset of cardiac failure, it has been assumed that, prior to the attack, slower, normal rhythm was arising in the sino-auricular node although there was no definite evidence of this.

In Case 3 the cardiac rhythm was originating from the auriculo-ventricular node when he was first seen and later appeared to arise from an ectopic auricular focus: there has never been any evidence of a normal sino-auricular node. It is impossible to say how long the abnormal rhythm has been present but the reference to a "damaged heart" five years earlier suggests that it may have been present at that time. In Case 2 there is evidence that a normal sino-auricular node is present as the one record that was obtained during carotid sinus pressure does show normal $P$ waves. However, during the whole of the period she has been under observation, this is the only time they have been shown. During the paroxysm of tachycardia that was recorded the rhythm arose in the auriculo-ventricular node; subsequently it transferred to an ectopic auricular focus where it has persisted. In Case 1 digitalization demonstrated the presence of a normal sino-auricular node but it seems possible that this node had never initiated the cardiac cycle prior to treatment.

\section{SUMMARY}

Three cases of persistent ectopic auricular tachycardia in children are described. In one case there was no evidence of the existence of a normal sino-auricular node. In none of the three cases did persistent tachycardia at a high rate over a long period lead to the development of cardiac failure, though in one there were some signs of failure when the rate was unusually fast.

We wish to thank Sir John Parkinson and Professor John Hay for their help in the preparation of this paper, and Professor N. B. Capon and Dr. F. P. Hudson for allowing us access to Cases 2 and 3 . We also wish to express our appreciation of the enthusiasm and skill displayed by Messrs. E. J. Caldwell and W. E. Lake in obtaining the electrocardiograms.

\section{RFFERENCES}

Alimurung, M. M., Eley, R. C., and Massell, B. F. (1950). Amer. Heart J., 40, 468.

Campbell, M. (1947). Lancet, 2, 641.

Claiborne, T. S. (1950). Amer. Heart J., 39, 444.

Herson, R. N., and Willington, F. L. (1947). Brit. Heart J., 9, 19.

Hubbard, J. P. (1941). Amer. J. Dis. Child., 61, 687.

Maddox, K. (1937). Amer. Heart J., 14, 183.

Miller, R., and Perelman, J. S. (1945). Amer. Heart J., 29, 555.

Parkinson, J., and Papp, C. (1947). Brit. Heart J., 9, 241.

Weiss, H. B., and McGuire, J. (1936). Amer. Heart J., 12, 585. 